\title{
Development and Evaluation of Silver Nanosystem-based Novel Antimicrobial Dental Stone
}

\author{
Jalis Aaisha Khan ${ }^{1}$, Kishore Ginjupalli ${ }^{2}$, Nagaraj Perampally Upadhya ${ }^{3}$, Nishanth Balachandran Bhat ${ }^{4}$, Tarun Awatramaney ${ }^{5}$, \\ Saleemulla Khan ${ }^{6}$, Mamta Ballal ${ }^{7}$
}

\begin{abstract}
Aim: To find a suitable disinfectant additive with effective antimicrobial activity and physical properties to dental gypsum product. Methods and materials: Design and settings of the study involved three compounds; Silver nitrate $(0.3 \%, 0.5 \%, 1 \%)$; Copper Sulfate $(0.5 \%$ and $1 \%)$, and Potassium Permanganate ( $0.5 \%$ and $1 \%)$. Antimicrobial properties, setting time, compressive strength (1 hour and 24 hours) and reproduction of surface details were evaluated. Standard strains of Staphylococcus aureus, Pseudomonas aeruginosa, Escherichia coli, and Candida albicans were used in the study. Dental stone was mixed with test compounds and plain water (control) were sampled in punch well on agar plates which were incubated at $37^{\circ} \mathrm{C}$ for 24 hours. Mean of Minimum Inhibitory Zone (MIZ) in mm, was measured at 24 hours. The setting time was measured by standard indentation, Compressive strength using Universal testing machine and reproduction of surface details as per ADA guidelines. Statistical analysis of the data was done using one-way ANOVA with Tukey's post hoc test using Graph pad Prism Version 5. $p$-value of $<0.05$ was considered as statistically significant.

Results: Silver nitrate showed excellent antimicrobial activity against all the microorganisms. The setting time with $0.5 \%$ Silver nitrate was between 30 and 34 minutes, the compressive strength was found to be greater than the control and the surface details were acceptable. Thus, $0.5 \%$ silver nitrate was reported as an alternative disinfectant for gypsum products.

Conclusion: An amount of $0.5 \%$ silver nitrate could be safely suggested as suitable disinfectant additive for gypsum product.

Clinical significance: The antimicrobial property imparted to the stone reduces the risk of cross-infection among dental personnel, patients and lab personnel from bacterial, viral, and fungal microorganisms that remain even viable after cleansing and disinfecting the impressions. Keywords: Antimicrobial activity, Copper sulfate, Dental stone, Disinfectants, Inhibitory zone, Potassium permanganate, Silver nitrate.

World Journal of Dentistry (2022): 10.5005/jp-journals-10015-1914
\end{abstract}

\section{INTRODUCTION}

Cross-infections and their control is a major issue in medical, dental, and nursing setups. A wide spectrum of diseases could be transmitted from materials of daily use. One such product is Gypsum. American Dental Association (ADA), along with Centre for Disease Control in 2003 republished changed rules for epidemic control in dental health care settings (Control and Prevention 2003). ${ }^{1}$ National Association of Dental Laboratories has established Dental Laboratory Infection Control Council to have comprehensive training in infection control in the member dental laboratories. ${ }^{2}$ However, such obligations are not organized strictly and no such learning programs are conducted in developing countries. The British Dental Association (BDA) states that "infection control is the main focus of dental practice" and the BDA fully maintains its delegates in gaining superiority in this sector (2003). ${ }^{3}$ The state of cross infection is therefore, a prime issue to be taken up at all the stages of control. In dentistry, the intensity of plaster and stone usage is far more than any other dental material. ${ }^{4}$ The gypsum products also legitimize an apparent infection as a vector. According to a study involving 60 dental colleges in India, $75.9 \%$ of the respondents said that they disinfect dental impression under running water, while $24.1 \%$ of the respondents revealed that they adopt chemical disinfection methods. ${ }^{5}$ However, till date there is no globally accepted disinfection protocol for the safe disinfection of dental impressions and casts. ${ }^{2,6}$ The microorganisms harboring on the impressions may remain adherent to the position even after disinfection for the scheduled time by the manufacturer. ${ }^{6}$ Several metallic salts are
${ }^{1}$ Department of Dental Materials, AJ Institute of Dental Sciences, Kuntikan, Mangaluru, Karnataka, India

${ }^{2,3}$ Department of Dental Materials, Manipal College of Dental Sciences, Manipal, Karnataka, India

4,7Department of Microbiology, Melaka Manipal Medical College, Manipal, Karnataka, India

${ }^{5}$ Angel Cosmos Spring Dental Clinic, Owala, Thane, West, Maharashtra, India

${ }^{6}$ P.A. College of Pharmacy, Mangaluru, Karnataka, India

Corresponding Author: Saleemulla Khan, P.A. College of Pharmacy, Mangaluru, Karnataka, India, Phone: +919916877900, e-mail: principal.pacp@pace.edu.in

How to cite this article: Khan JA, Ginjupalli K, Upadhya NP, et al. Development and Evaluation of Silver Nanosystem-based Novel Antimicrobial Dental Stone. World J Dent 2022;13(2):104-109.

Source of support: Nil

Conflict of interest: None

recognized to be effective antimicrobial agents and ingrained in dental and preventive operations. ${ }^{7-9}$ However, they have not been combined into gypsum products. Laboratory personnel cannot consistently accept personnel protective appliances such as gloves, specifically being on the lathe machines; therefore, infections can be transmitted through skin abrasions or lacerations of empty parts. Several serological investigations have demonstrated that dental health care personnel have a slightly larger incidence of HBV disease than the general community. ${ }^{10,11}$ An impression,

(OThe Author(s). 2022 Open Access This article is distributed under the terms of the Creative Commons Attribution 4.0 International License (https://creativecommons. org/licenses/by-nc/4.0/), which permits unrestricted use, distribution, and non-commercial reproduction in any medium, provided you give appropriate credit to the original author(s) and the source, provide a link to the Creative Commons license, and indicate if changes were made. The Creative Commons Public Domain Dedication waiver (http://creativecommons.org/publicdomain/zero/1.0/) applies to the data made available in this article, unless otherwise stated. 
if not sterilized, can cross-infect the full laboratory sector by back and forth propagation between laboratory and clinical area. An alternative or additional approach to cast/impression disinfection is to decontaminate the cast produced from the impression by consolidating a sterilizing chemical into the gypsum. ${ }^{12}$ Hence, in the proposed investigation, an experiment has been designed and performed to use metallic salts as an antimicrobial agent in dental stone and to determine their efficacy in preventing infection and their inertness toward physical properties of dental stone products.

\section{Methods and Materials}

The materials used in the study includes the Dental Stone (Denstone, Pankaj Enterprises, Bhopal, MP, India), silver nitrate, potassium permanganate, copper sulfate (analytical grade Ranbaxy 6CAV0120, Punjab, India) SDA (Sabouraud dextrose agar), and Mueller Hinton Agar were purchased from Hi-media, Mumbai, India. Chlorhexidine and sterile water was procured from Pharmacy Dispensing wing, Kasturba Hospital, Manipal, India.

A pilot investigation with 12 disinfectant additives viz. ethyl alcohol (70\%), iodine (5\%, $1 \%, 0.5 \%)$, sodium hypochlorite (1\%), copper sulfate $(0.5 \%, 1 \%)$, potassium dichromate $(0.5 \%, 1 \%)$, chlorhexidine $(0.2 \%)$, thymol( $1 \%)$ silver nitrate $(0.3 \%, 0.5 \%, 1 \%)$, sodium citrate $(0.5 \%)$; potassium hydrogen phthalate $(0.5 \%, 1 \%)$, phenolphthalein $(0.5 \%)$, and potassium permanganate $(0.5 \%, 1 \%)$; in dental stone was performed to study their influence on setting time. Medical and dental literature authenticates the use of these additives as potential disinfectants in several medical and dental conditions. Several studies have been conducted and many are used as successful disinfectants. ${ }^{13-23}$ The criteria for selection of these 12 disinfectants was to sublimate the materials with best antimicrobial properties and physical properties. The setting time of these components was measured as mentioned by ADA specification number 25 employing the standard indentation process. Antimicrobial agents having least influence on setting time were selected for further investigation. Silver nitrate $(0.3 \%, 0.5 \%, 1 \%)$, copper sulfate $(0.5 \%$ and $1 \%)$ and potassium permanganate $(0.5 \%$ and $1 \%)$ displayed least influence and hence selected for the further investigation. All handlings involving microbiological procedures were performed by a controlled barrier approach for evaluation of antimicrobial activity under asepsis laboratory techniques, including plating, inoculating etc. were carried out in a laminar air flow (M.C. Dalal Agencies, Chennai, India) cabinet hood (Mitchell and Carter 2000). The Standard strains of Staphylococcus aureus, Pseudomonas aeruginosa, Escherichia coli, and Candida albicans were adopted throughout the study. Mueller-Hinton agar medium was used for S.aureus, P.aeruginosa, E.coli while Sabouraud dextrose broth was used for C. albicans. Inoculated plates were incubated at $37 \hat{A}^{\circ} \mathrm{C}$ for 8 hours after which microbial suspensions were standardized by dilution of the cultured organisms with sterile broth to a density visually comparable to barium sulfate standard-McFarland tube number $5 .{ }^{24}$ Inoculation of agar plates with microbial species by agar punch well method was done by the using diluted $0.5 \mathrm{~mL}$ solution of microbial species which was dispensed onto each sterile Mueller-Hinton and Sabouraud's dextrose agar plates and a lawn culture was established. After the inoculums dried, $6 \mathrm{~mm}$ diameter well was punched to an intensity of $5 \mathrm{~mm}$ utilizing a sterile punch cork borer. ${ }^{24}$ Specimens of dental stone with disinfectant were prepared by mixing $100 \mathrm{gm}$ of dental stone with measured volume of water stone. Required amount of antimicrobial agent was either weighed or measured volumetrically and added to mixing water. Mixing water containing disinfectant solution was taken into a clean vacuum mixing bowl and preweighed amount of dental stone was slowly added by shifting method. After the addition of dental stone powder, mixing was carried out with plaster spatula for 10 seconds to ensure complete wetting of the powder and mixing liquid. After this, the mixing bowl was attached to vacuum and mechanical mixing was carried out for 30 seconds. At the end of the mixing a uniform creamy mix was obtained and the same was used as specimen preparation. Dental stone mixed with plain water was used as control. Antimicrobial activity of dental stone was assessed by blending with either pure water (control) or disinfectant solution was directly placed into the punch wells in the agar plates. Plates were again incubated at $37^{\circ} \mathrm{C}$ in an incubator for 24 hours. Mean inhibitory zone (MIZ) in $\mathrm{mm}$, for each analysis punch together was assessed after 24 hours $(n=6)$.

Evaluation of physical properties was done byconducting three different tests viz.: Measurement of setting time; compressive strength, and reproduction of surface details. Setting time measurements were performed by using the standard indentation approach. An amount of $50 \mathrm{gm}$ of dental stone was incorporated with $15 \mathrm{~mL}$ of antimicrobial solution or plain water as demonstrated formerly and was transferred on to a clean glass plate. The surface of the blend was smoothened using plaster spatula. Initial and final setting times were tested by smaller and bigger Gillmore needles. Gillmore needle (smaller/ bigger) was gently lowered onto the surface of the dental stone mixture and passed to indent the surface. When Small needle failed to indent it was considered as initial setting time, while, the final setting time was recorded when bigger needle failed to indent $(n=3)$. The evaluation of compressive strength of prepared samples was compliant with ADA specification number 25. A Split metal mould measuring $20 \mathrm{~mm}$ in diameter and $40 \mathrm{~mm}$ in height was greased with vaseline and arrayed on a glass plate. The dental stone mix was slowly poured into the mould under vibration until the mold was overfilled. Overfilled mold was covered with another glass slab and the material was allowed to set for 45 minutes. After the specimens were retrieved, they were stored at room temperature until further testing. Compressive strength of test specimens was measured at 1-hour (wet strength) and 24-hour (dry strength) after preparation. The cylindrical specimens of dental stone were placed in the lower plate of universal testing machine (Instron, 3366, UK). Further, the specimens were stressed at a loading rate of $0.5 \mathrm{~mm} / \mathrm{min}$ until fracture. Maximum load during the testing was noted and divided by the area of the specimen to obtain the strength $(n=6)$. For the Reproduction of surface details, the tests were conducted, as recommended by the ADA specification no. $19^{25}$ and in accordance with the International Standard ISO $4823,{ }^{26}$ a standardized stainless steel die was used for impression making. The metal dye had three horizontal lines intersected by two vertical lines. Before recording each impression, the die was wiped with ethanol and allowed to dry at room temperature. Initially an alginate impression of a preformed metal die containing thin lines of 25 micron width was obtained. A mix of dental stone with either water or disinfectant solution was then poured into the impression under vibration. Poured impressions were allowed to set for 45 minutes. After setting, the stone cast was restored and noted for reproduction of surface details by visual correlation by a margin of three observers and scoring of the analyze reproduction was transferred out as supports. After setting, the stone cast was restored and followed for reproduction of surface details by visual comparison by a minimum of three observers and scoring was done as given below.

\section{- Value 1 indicated-Sharp detail with continuous lines.}


- Value 2 indicated-Extended lines but with some loss of sharpness.

- Value 3 indicated-Deterioration of line details.

- Value 4 indicated-Rough appearance with loss of continuity of the line.

The statistical analyses of data were done by one-way ANOVA with Tukey's post hoc test using Graph pad Prism Version 5.0 $p$-value of $<0.05$ or less was considered to be statistically significant.

\section{Results}

Antimicrobial Activity against various microorganisms (Fig. 1) and Table 1.

Antimicrobial activity of silver nitrate, copper sulfate, and potassium permanganate against Chlorhexidine as standard was measured in MIZ. Silver nitrate at $1 \%$ and $0.5 \%$, showed MIZ of 10 to $12 \mathrm{~mm}$ against all the organisms tested; S. aureus, $E$. coli, P.aureginosa, and C.albicans. Other additives were found effective against S.aureus alone. The results of initial and final setting time dental stone of control was found to be 15.27 minutes and 20.26 minutes, respectively. The initial setting time with $1 \%$ $\mathrm{CuSO}_{4}$ was least with 3.49 minutes while $0.5 \% \mathrm{AgNO}_{3}$ showed better setting with 14.44 minutes, close to control. The final setting time on the other hand was least with $1 \% \mathrm{CuSO}_{4}$ with 11.45 minutes, and maximum when incorporated with $1 \% \mathrm{AgNO}_{3}$ (42.37 minutes). Table 1 shows detail results values of the compressive strength of dental stone with disinfectant additives was found to be significantly different from the control specimens. One hour strength was considered as wet strength and 24 hourr strength was considered as dry strength. The control had wet strength of $(4.39 \pm 0.101) \mathrm{MPa}$, and dry strength $(5.432 \pm 0.52)$ $\mathrm{MPa}$. $\mathrm{CuSO}_{4}$ at $0.5 \%$ had highest wet strength of $(14.08 \pm 1.670)$ and the wet strength $1 \% \mathrm{CuSO}_{4}$ was least $(5.018 \pm 0.6070) \mathrm{MPa}$ among the group. Compared to control the dry strength was maximum with $1 \% \mathrm{AgNO}_{3}$ and least with $1 \% \mathrm{KmNO}_{4}$. Table 2 shows the details of results the compressive strength of dental stone in (MPa). The surface detail reproduction of the dental stone was not significantly decreased for most disinfectant materials. Except for $0.5 \%$ silver nitrate, all of the disinfectant mixed dental stones have scored 2 or less indicating better reproduction of surface details and $1 \%$ potassium permanganate showed best surface

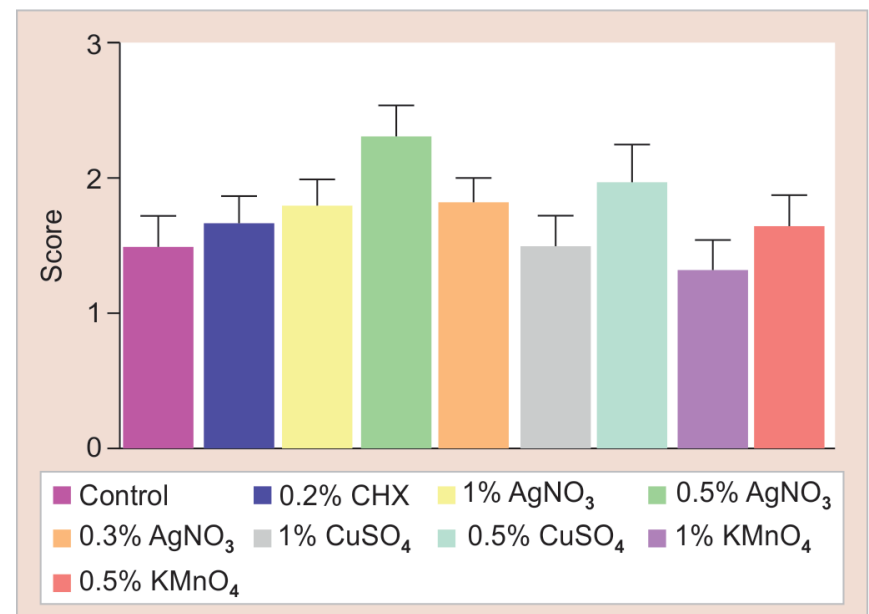

Fig. 1: Reproduction of surface details on dental stone incorporated with various additives detail reproduction. Inappropriate disinfection of the impressions may possibly result in contamination of dental casts making them potential source of cross contamination between the dental clinic and laboratory personnel. Hence, it is important to have a barrier system in place to prevent transfer of diseases. ${ }^{26,27}$ Therefore, the present study was designed to gauge the effect of a disinfectant additive on microbial deposits and physical properties of the dental stone. In the present study, metallic salts are used as disinfectant additives which exhibit certain amount of germicidal actions in a concentration dependent manner. ${ }^{7-9}$ Salts of silver and copper are widely used in Dentistry and Medicine as antimicrobial agents, their mechanism of action is attributed to their ability to act as protein coagulants and the capacity to combine with free sulfhydryl groups of all enzymes. ${ }^{28}$ Therefore, it was considered worthwhile to use these salts in the dental stone. Potassium permanganate a strong oxidizing agent, has been used in oropharyngeal cleansing and in nosocomial pneumonia in critically ill patients. Hence it was used as a disinfectant additive in our study. Four commonly residing oral organisms namely S. aureus, E. coli, P. aureginosa, and C.albicans were selected for the study. Silver nitrate, copper sulfate, and potassium permanganate at two concentrations of each $(0.5,1 \%)$ were selected as disinfectant additive after a pilot study. The salts true to their properties showed excellent antimicrobial activity against all the microorganisms studied. Silver nitrate exhibited significant antimicrobial properties $(p<0.001$ in all organisms except $E$. coli). The MIZ of silver nitrate against $E$ coli. was lesser $(p<0.05)$ than gram positive bacteria, suggesting requirement of higher concentration of silver nitrate to contain gram negative organism. Gram-positive bacteria have more peptidoglycan which is negatively charged, than gram-negative bacteria. Silver ions being positively charged get easily trapped by peptidoglycan in gram positive bacteria and therefore a lower concentration of silver nitrate is more efficient in killing gram positive bacteria than gram-negative organisms. ${ }^{28}$ Copper sulfate $(0.5 \% \& 1 \%)$ and potassium Permanganate ( $0.5 \%$ and $1 \%$ ) incorporated Dental stones did not show antimicrobial activity against any of the organisms selected except for staphylococcus aureus $(p<0.001)$, although they are known antimicrobials. However, their low concentrations barred their activity. The activity of Chlorhexidine, the standard selected for comparison was found to be $\mathrm{pH}$ dependent and that was greatly reduced in the presence of organic matter. However, it was found that the uptake of chlorhexidine by E. coli and S. aureus was very rapid and concentration and $\mathrm{pH}$ depended. ${ }^{29}(p<0.001)$.The results of setting time of additives obtained in the study are similar to the previous studies in which the setting time was prolonged due to increase in the concentration of water substitutes. ${ }^{30}$ Silver nitrate $(0.5$ and $1 \%)$ and potassium permanganate $(1 \%)$ showed similar setting time as control while copper sulfate (0.5\% and $1 \%)$ and potassium permanganate $(0.5 \%)$ showed a decrease in initial setting time ( $p<0.05$ when compared to control) of dental stone. Reduction in the initial setting time with copper sulfate could be due to the common ion effect which results in rapid reaction of hemihydrate and altered solubility of hemihydrate and dihydrate, reducing the initial setting time. Furthermore, formation of potassium sulfate accelerates setting of dental stone thus reduces initial and final setting time. ${ }^{31,32}$ Although $0.2 \% \mathrm{CHX}$ showed reduced initial setting time than the control, the results were within the specification limits of ISO $6873^{33}$ Silver nitrate, on the contrary, showed a significant increase in the final setting time of dental stone at both the concentrations $(p<0.01$ against control) 
Nano Silver-based Dental Stone

Table 1: Antimicrobial activity of various additives in dental stone

\begin{tabular}{|c|c|c|c|c|c|c|c|c|c|}
\hline Variable & Control & $0.2 \% \mathrm{CHX}$ & $1 \% \mathrm{AgNO}_{3}$ & $0.5 \% \mathrm{AgNO}_{3}$ & $0.3 \% \mathrm{AgNO}_{3}$ & $0.5 \% \mathrm{CuSO}_{4}$ & $1 \% \mathrm{CuSO}_{4}$ & $0.5 \% \mathrm{KMnO}_{4}$ & $1 \% \mathrm{KMnO}_{4}$ \\
\hline S.aureus & NS & $\begin{array}{l}9.94 \pm \\
0.0966\end{array}$ & $\begin{array}{l}12.00 \pm \\
0.2582^{\mathrm{a}}\end{array}$ & $\begin{array}{l}12.00 \pm \\
0.2582^{\mathrm{a}}\end{array}$ & $\begin{array}{l}11.00 \pm \\
0.3651^{\mathrm{a}}\end{array}$ & $\begin{array}{l}11.00 \pm \\
0.3651^{\mathrm{a}}\end{array}$ & $\begin{array}{l}11.50 \pm \\
0.3416^{a}\end{array}$ & $\begin{array}{c}11.00 \pm \\
0.2582^{a}\end{array}$ & $\begin{array}{c}10.00 \pm \\
0.2582^{\mathrm{a}}\end{array}$ \\
\hline C.albicans & NS & $\begin{array}{l}6.82 \pm \\
0.1161\end{array}$ & $\begin{array}{l}10.00 \pm \\
0.2582\end{array}$ & $\begin{array}{l}12.00 \pm \\
0.2582\end{array}$ & $\begin{array}{l}12.00 \pm \\
0.3651\end{array}$ & NS & NS & NS & NS \\
\hline P.auregenosa & NS & $\begin{array}{l}5.66 \pm \\
0.0962\end{array}$ & $\begin{array}{l}10.00 \pm \\
0.3651\end{array}$ & $\begin{array}{l}12.00 \pm \\
0.2582\end{array}$ & $\begin{array}{l}10.00 \pm \\
0.2582\end{array}$ & NS & NS & NS & NS \\
\hline E coli & NS & $\begin{array}{l}5.64 \pm \\
0.0021\end{array}$ & $\begin{array}{l}10.00 \pm \\
0.3651\end{array}$ & $9.00 \pm 0.3651$ & $8.00 \pm 0.2582$ & NS & NS & NS & NS \\
\hline
\end{tabular}

Results are expressed as Mean $\pm S ; n=6$

$\mathrm{a}=p<0.001 \mathrm{~V} / \mathrm{s}$ control, $\mathrm{b}=p<0.001 \mathrm{~V} / \mathrm{s} \mathrm{CHX}$;

$\mathrm{c}=p<0.005 \mathrm{~V} / \mathrm{s} \mathrm{CHX}$

Table 2: Initial and final setting time (in minutes) of disinfectants additives in dental stone

\begin{tabular}{lccccccccc}
\hline Variables & Control & $0.2 \% \mathrm{CHX}$ & $1 \% \mathrm{AgNO}_{3}$ & $0.5 \% \mathrm{AgNO}_{3}$ & $0.3 \% \mathrm{AgNO}_{3}$ & $1 \% \mathrm{CuSO}_{4}$ & $0.5 \% \mathrm{CuSO}_{4}$ & $1 \% \mathrm{KMnO}_{4}$ & $0.5 \% \mathrm{KMnO}_{4}$ \\
\hline Initial setting time & $15.27 \pm$ & $11.12 \pm$ & $14.08 \pm$ & $14.44 \pm$ & $14.62 \pm$ & $3.487 \pm$ & $6.330 \pm$ & $15.28 \pm$ & $8.523 \pm$ \\
& 0.1202 & 0.0624 & $0.2646^{\mathrm{a}, \mathrm{d}}$ & $0.0305^{\mathrm{b}, \mathrm{e}}$ & $0.2048^{\mathrm{f}}$ & $0.0606^{\mathrm{c}}$ & $0.0404^{\mathrm{c}}$ & 0.1244 & 0.3251 \\
Final setting time & $20.26 \pm$ & $16.20 \pm$ & $42.37 \pm$ & $36.22 \pm$ & $24.54 \pm$ & $11.45 \pm$ & $29.30 \pm$ & $20.57 \pm$ & $14.98 \pm$ \\
& 0.1212 & $0.0577^{\mathrm{c}}$ & $0.0472^{\mathrm{d}}$ & $0.0907^{\mathrm{d}}$ & $0.2524^{\mathrm{d}}$ & $0.0781^{\mathrm{a}}$ & $0.6061^{\mathrm{a}}$ & 0.2347 & $0.4168^{\mathrm{b}}$ \\
\hline
\end{tabular}

Results are expressed as Mean $\pm \mathrm{SE} ; n=6$

$\mathrm{a}=(p<0.001 \mathrm{~V} / \mathrm{s} \mathrm{ctrl}) ; \mathrm{b}=(p<0.005 \mathrm{~V} / \mathrm{s} \mathrm{ctrl}) ; \mathrm{c}=(p<0.01 \mathrm{v} / \mathrm{s} \mathrm{ctrl})$;

$\mathrm{d}=(p<0.001 \mathrm{~V} / \mathrm{s} \mathrm{CHX}) ; \mathrm{e}=(p<0.005) \mathrm{v} / \mathrm{s} \mathrm{CHX})$

Table 3: Compressive strength (in mpa) of disinfectant additives in dental stone after 1 hour and 24 hours

\begin{tabular}{lccccccccc}
\hline Variables & Control & $0.2 \% \mathrm{CHX}$ & $1 \% \mathrm{AgNO}_{3}$ & $0.5 \% \mathrm{AgNO}_{3}$ & $0.3 \% \mathrm{AgNO}_{3}$ & $1 \% \mathrm{CuSO}_{4}$ & $0.5 \% \mathrm{CuSO}_{4}$ & $1 \% \mathrm{KMnO}_{4}$ & $0.5 \% \mathrm{KMnO}_{4}$ \\
\hline 1 h compres- sive & $4.390 \pm$ & $12.72 \pm$ & $7.870 \pm$ & $10.81 \pm$ & $8.222 \pm$ & $5.018 \pm$ & $14.08 \pm 1$ & $7.718 \pm$ & $6.462 \pm 0.7384$ \\
strength & 0.5051 & $0.8952 \mathrm{a}$ & 0.7382 & $1.834 \mathrm{~b}$ & 1.128 & 0.6070 & $.670 \mathrm{c}, \mathrm{d}$ & 0.9880 & \\
24 h compres- sive & $5.432 \pm$ & $14.44 \pm$ & $9.624 \pm$ & $8.782 \pm$ & $9.580 \pm$ & $8.630 \pm$ & $7.274 \pm$ & $7.046 \pm$ & $9.680 \pm 0.7059$ \\
strength & 0.52 & $0.70 \mathrm{a}$ & 1.622 & 1.042 & 2.210 & 1.315 & 0.4472 & 1.376 & \\
\hline
\end{tabular}

Results are expressed as Mean \pm SE: $n=6$

$\mathrm{a}=p<0.001$ vs control, $\mathrm{b}=p<0.005 \mathrm{~V} / \mathrm{s}$ CTRL; $\mathrm{b}={ }^{* *} \mathrm{~V} / \mathrm{s} \mathrm{ctrl}$

$\mathrm{c}={ }^{* * *} \mathrm{~V} / \mathrm{s} \mathrm{ctrl} ; \mathrm{d}={ }^{* * *} \mathrm{~V} / \mathrm{s} \mathrm{CHX}$

due to reaction with the calcium sulfate which produces calcium nitrate. This reaction prolongs the final setting time of dental stone.

$$
2 \mathrm{AgNO}_{3}+\mathrm{CaSO}_{4} \longrightarrow \mathrm{Ag}_{2} \mathrm{SO}_{4}+\mathrm{Ca}\left(\mathrm{NO}_{3}\right)_{2}
$$

Further, presence of $\mathrm{Ag}^{+}$ions at nucleating sites may reduce crystal growth and intermeshing of the crystals resulting in longer final setting time. Due to this, formation of dihydrates could be reduced as the presence of silver ions prevents the crystal growth and intermeshing, thereby increasing the final setting time. However, the initial setting time was almost same as water without additives. This phenomenon needs to be probed further. Potassium permanganate at $1 \%$ concentration showed a similar behavior as that of silver nitrate. The behavior of potassium ions at higher concentrations may mimic the behavior of Silver ions. The implications of compressive strength with additives or water substitute in the present study are in agreement with previous studies. The wet strength of dental stone mixed with chlorhexidine solution was found to be superior to the control specimens with, no significant increase in dry strength. This could be attributed to the rapid setting of the dental stone resulting in more entanglement and intermeshing of crystals during the first hour. ${ }^{19}$ Similar increase in compressive strength was observed with silver nitrate, copper sulfate and potassium permanganate $(p<0.05$ against water) at lower concentrations which is attributed to the rapid crystallization of dental stone. ${ }^{15,19}$ However increased concentration of disinfectant additives was found to reduce the strength of dental stone. The same effect was seen in previous studies which explains that the presence of additives between the gypsum crystals prevents entanglement and intermeshing of growing gypsum crystals. ${ }^{15,19}$ resulting in weaker gypsum matrix leading to fracture under low stresses..$^{15,22}$ The outcomes of Reproduction of surface details in the dental stone mixed with chlorhexidine, silver nitrate, copper sulfate, and potassium permanganate were found to be comparable and reproducible. This property depends on the ability of dental stone to wet the surface of the impression and also on the fluidity of the mix. When the dental stone mix is of low viscosity, it flows into the details of the impression and reproduces the details. A slow setting material helps in better reproduction of details. Results of the present study are in support of the previous investigations which showed that dental stone surfaces mixed with disinfectant were slightly coarser than normal stone surfaces. ${ }^{3,34}$ Even though it was observed that the setting time was getting reduced by the addition of additives, studies have shown that incorporation of disinfecting solutions do not interfere with the detail reproduction capacity of dental gypsum ${ }^{35}$ (Table 3 ).

\section{Conclusion}

In our study Silver nitrate at all the three percentages $(0.3 \%, 0.5 \%$, and $1 \%)$ showed excellent antimicrobial activity against all the 
four microorganisms compared to the other test samples. The final setting time with $0.5 \%$ silver nitrate was between 30 and 34 minutes which is practically acceptable, the compressive strength of $0.5 \%$ silver nitrate was greater than the control but slightly less than the standard, and the surface details of silver nitrate at all the percentages are acceptable. Thus, considering all the above results, it can be concluded that $0.5 \%$ silver nitrate could be a better alternative disinfectant for gypsum product.

\section{Clinical Significance}

The study infers that silver nitrate could act as a potent antimicrobial additive in dental stone to minimize the cross infection among patients and dental healthcare personnel (DHCP) in dental settings. Hence, proficient knowledge, right attitude, and prompt practice toward infection control is very essential in the current times of surging microbial infections and antimicrobial resistance. Antimicrobial dental stone ensures infection control following the routine disinfection of impressions. This provides a safer working environment for dentists,dental health care personnel and the patients.

\section{Limitations and Further Scope}

Aim of the present study was to study the effect of various disinfectant additives on the properties of dental stone. Among the additives studied, silver nitrate has shown superior antimicrobial properties. However, other forms of silver such as colloidal silver and silver nano particles may be incorporated into the dental stone and their antimicrobial properties may be evaluated. Present study evaluated the antimicrobial activity against the commonly occurring microbial organisms.

\section{Acknowledgments}

The authors would like to thank the University of Manipal Academy of Higher Education, and its various departments, especially the department Pharmacognosy and Phytochemistry, Manipal College of Pharmaceutical Science (MCOPS), department of Microbiology and department of Chemistry, Kasturba Medical College (KMC). Their explicit talent, experience and guidance enabled to complete this interdisciplinary work.

\section{Funding Sources}

This research did not receive any specific grant from funding agencies in the public, commercial, or not-for-profit sectors.

\section{References}

1. Centers for Disease Control and Prevention. Guidelines for Infection Control in Dental Health-Care Settings - 2003. MMWR 2003; 52 (No. RR-17).

2. Runnells RR. An overview of infection control in dental practice. J Prosthet Dent 1988; 59(5):625-629. DOI: 10.1016/0022-3913(88)90083-2

3. British Dental Association, Advice sheet, infection control in dentistry. Centers for Disease control and prevention. Guidelines for Infection Control in Dental Health Care Setting- 2003. 2003/52(RR17);1-97.

4. Anderson, JN. Applied dental materials. Third ed. Blackwell scientific publications. Gypsum Products for Dental Casts 1972;179.

5. Marya CM, Shukla P, Dahiya V, et al. Current status of disinfection of dental impressions in Indian dental colleges: a cause of concern. J Infect Dev Ctries 2011;5(11):776-780. DOI: 10.3855/jidc.1652

6. Leung RL, Schonfeld SE. Gypsum casts as a potential source of microbial cross-contamination. J Prosthet Dent 1983;49(2):210-211. DOI: 10.1016/0022-3913(83)90503-6
7. Kawahara K, Tsuruda K, Morishita M, et al. Antibacterial effect of silver-zeolite on oral bacteria under anaerobic conditions. Dent Mater 2000;16(6):452-455. DOI: 10.1016/s0109-5641(00)00050-6

8. Pandian SR, Deepak V, Kalishwaralal K, et al. Mechanism of bactericidal activity of Silver Nitrate-a concentration dependent bi-functional molecule. Braz J Microbiol 2010;41(3):805-809. DOI: 10.1590/s1517-83822010000300033

9. Yang G Xiao, Guo-wei HZ, Chen L. Dimensional accuracy of dental gypsum casts after immersion in stable chlorine dioxide disinfectant Zhejiang Da Xue Xue Bao Yi Xue Ban 2010; 39 (3):318-321.

10. Goh KT, Chan YW, Womg LYM, et al. The prevalence of hepatitis B virus Markers in dental personnel in Singapore. Trans R Soc Trop Med Hyg 1988; 82(6)908-910. DOI: 10.1016/0035-9203(88)90038-7

11. Ammon A, Reichart PA, Pauli G, et al. Hepatitis band $C$ among Berlin Dental Personnel: incidence, risk factors and effectiveness of barrier prevention measures. 2000;125(2)407-413. DOI: 10.1017/s0950268899004537

12. Tebrock OC, Engelmeier RL, Mayfield TG, et al. Managing dental impressions and casts of patients with communicable diseases. Gen Dent 1989;37(6):490-495.

13. Thiruvenkadam G, Asokan S, John B, et al. Effect of $95 \%$ ethanol as a final irrigant before root canal obturation in primary teeth: an in vitro study. Int J Clin Pediatr Dent 2016;9(1):21-24. DOI: $10.5005 /$ jp-journals-10005-1327

14. Abbaszadegan A, Khayat A, Motamedifar M. Comparison of antimicrobial efficacy of $\mathrm{IKI}$ and $\mathrm{NaOCl}$ irrigants in infected root canals: an in vivo study. Iran Endod J 2010;5 (3):101-106

15. Türkün $M$, Türkün Ç, Kalender A. Effect of cavity disinfectants on the sealing ability of nonrinsing dentin-bonding resins. Quintessence Int 2004;35(6):469-476.

16. Schecter $A$, Pavuk $M$, Päpke $O$, et al. Potassium dichromate and ethyl alcohol as blood preservatives for analysis of chlorinated organics. Chemosphere 2003; 60:154-157. DOI: 10.1016/j. chemosphere.2004.04.062

17. Sharma V, Nainan MT, Shivanna V. The effect of cavity disinfectants on the sealing ability of dentin bonding system: an in vitro study. J Conserv Dent 2009;12(3):109-113. DOI: 10.4103/0972-0707.57634

18. Thosar N, Basak S, Bahadure RN, et al. Antimicrobial efficacy of five essential oils against oral pathogens: an in vitro study. Eur J Dent 2013;7(S 01):S071-S077. DOI: 10.4103/1305-7456.119078

19. Cruz-Filho AM, Sousa-Neto MD, Savioli RN, et al. Effect of chelating solutions on the microhardness of root canal lumen dentin. J Endod 2011;37(3):358-362. DOI: 10.1016/j.joen.2010.12.001

20. Pthalates an overview science direct topics https;//www.science direct.com/topics/earth and planetary science /phthalates (W.J.G.M. Peijnenburg, in Encyclopedia of Ecology, 2008)

21. Therapeutic composition formulated as a dental rinse that stimulates Prostaglandin synthesis in the mouth to prevent plaque buildup on the teeth and Periodontal disease patent by Inventor John E. McHugh.

22. Delgado-Enciso I, Madrigal-Perez VM, Lara-Esqueda A, et al. Topical $5 \%$ potassium permanganate solution accelerates the healing process in chronic diabetic foot ulcers. Biomed Rep 2018;8(2):156-159. DOI: 10.3892/br.2018.1038

23. Bonev B, Hooper J, Parisot J. Principles of assessing bacterial susceptibility to antibiotics using the agar diffusion method. J Antimicrob Chemother 2008;61(6):1295-1301. DOI: 10.1093/jac/dkn090

24. Amin WM, Al-Ali MH, Al Tarawneh SK, et al. The effects of disinfectants on dimensional accuracy and surface quality of impression materials and gypsum casts. J Clin Med Res 2009;1(2):81-89. DOI: $10.4021 /$ jocmr2009.04.1235

25. Lu H, Nguyen B, Powers JM. Mechanical properties of 3 hydrophilic addition silicone and polyether elastomeric impression materials. J Prosthet Dent 2004; 92(2):151-154. DOI: 10.1016/j.prosdent.2004.05.016

26. Lucas MG, Arioli-Filho JN, Nogueira SS, et al. Effect of incorporation of disinfectant solutions on setting time, linear dimensional stability, and detail reproduction in dental stone casts. 
J Prosthodont 2009;18(6):521-526. DOI: 10.1111/j.1532-84 9X.2009.00466.x

27. Zakaria MR, Johnston WM, Reisbick MH, et al. The effect of the liquid dispensing agent and a microcrystalline additive on the physical properties of Type IV gypsum. J Pros Dent 1988; 60(5):630-637.

28. Russell AD, Day MJ Antibacterial activity of chlorhexidine, J Hosp Infect 1993; 25(4);229-238.

29. Labeeb RM, Jaffer NT. Effectiveness of some disinfection solutions on compressive strength and Hardness properties of two types of dental stones JODR 2019;6;(2):47-58.

30. Jaffer NT. Effectiveness ofsome disinfectant solutions on the compressive strength and hardness properties of two types of dental stone. JODR 2019;6(2).
31. Powers, JM, Sakaguchi, RL. (2006) Craig's Restorative Dental Materials 12th Edition, Mosby, Missouri, 2006.386-393.

32. Kenneth J. Anusavice, Phillps' Science of Dental Materials 11th Edition Philidelphia, Saunders an Imprint of Elsevier.2003.269.

33. ISO 6873. Dental gypsum products. International Organization for Standardization. 3rd ed. Geneva: Switzerland; 2013.

34. Taqa AA, Mohammed NZ, Bash TY. The effect of adding some chemical materials on the water powder ratio of dental stone. IJAHMR 2018; 2(7): 13-17.

35. Abdelaziz KM, Combe EC, Hodges JS. The effect of disinfectants on the properties of dental gypsum: 1. mechanical properties. J Prosthodont 2002;11(3):161-167. DOI: 10.1053/jopr. 2002.126860 